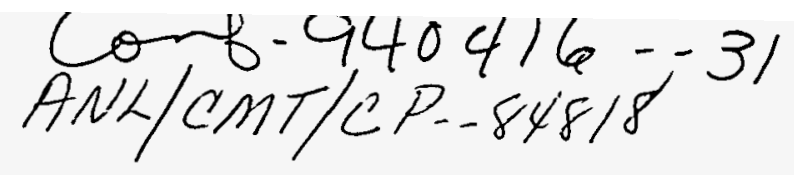

\title{
Ab Initio Calculations for Dissociative Hydrogen Adsorption on Lithium Oxide Surfaces*
}

\author{
A. Sutjianto, ${ }^{a, b}$ S. W. Tam, ${ }^{a}$ R. Pandey, ${ }^{b}$ L. A. Curtiss, ${ }^{a}$ and C. E. Johnson ${ }^{a}$ \\ ${ }^{a}$ Chemical Technology Division, Argonne National Laboratory, Argonne, II 60439-4828 \\ b Physics Department, Michigan Technological University, Houghton, MI 49931-1295
}

Key words: lithium oxide, dissociative hydrogen, chemisorption, density of states, ceramics, surfaces, fusion

To be presented at

Fabrication and Properties of Ceramics for Fusion Energy Symposium

American Ceramics Society Annual Meeting

Indianapolis, $\mathbb{N}$

April 24-28, 1994,

and submitted to

The Journal of Nuclear Materials

\begin{abstract}
DISTRIBUTION OF THIS DOCUMENT IS UNLIMITED
Yos.
"Work supportred by the U.S. Department of Energy, Office of Fusion Energy, under Contract W-31-109-Eng-38.

\section{DISCLAIMER}

\begin{abstract}
This report was prepared as an account of work sponsored by an agency of the United States Government. Neither the United States Government nor any agency thereof, nor any of their employees, makes any warranty, express or implied, or assumes any legal liability or responsibility for the accuracy, completeness, or usefulness of any information, apparatus, product, or process disclosed, or represents that its use would not infringe privately owned rights. Reference herein to any specific commercial product, process, or service by trade name, trademark, manufacturer, or otherwise does not necessarily constitute or imply its endorsement, recommendation, or favoring by the United States Government or any agency thereof. The views and opinions of authors expressed herein do not necessarily state or reflect those of the United States Government or any agency thercof.
\end{abstract}




\section{DISCLAIMER}

Portions of this document may be illegible in electronic image products. Images are produced from the best available original document. 


\begin{abstract}
Dissociative hydrogen chemisorption on the $\mathrm{Li}_{2} \mathrm{O}$ surfaces of the (100), (110), and (111) planes has been investigated with $a b$ initio Hartree-Fock calculations. Calculations for unrelaxed crystal $\mathrm{Li}_{2} \mathrm{O}$ structures indicated that except for the (100) surface, the (110) and (111) surfaces are stable. Results on the heterolytic sites of n-layer (110) (where $\mathrm{n} \geq 2$ ) slabs and three-layer (111) slabs suggest that dissociative hydrogen chemisorption is endothermic. For a one-layer (110) slab at $100 \%$ surface coverage, the dissociative hydrogen chemisorption is exothermic, forming $\mathrm{OH}$ and $\mathrm{Li}^{+} \mathrm{HLi}^{+}$. The results also indicate that the low coordination environment in surface step structures, such as kinks and ledges, may play an important role in the hydrogen chemisorption process. On the homolytic sites of the (110) and (111) surfaces, there is no hydrogen chemisorption.
\end{abstract}




\section{Introduction}

Lithium ceramic are one class of materials being considered as tritium breeders for fusion technology. Hydrogen is known to enhance the release of tritium from lithium ceramic materials. This "accelerator" role of hydrogen has been demonstrated in numerous in-pile experiments on tritium release [1-5]. The enhancement effect is usually accomplished by the addition of hydrogen (typically at a level of around $0.1 \%$ ) to the helium purge gas. Despite this benefit, the use of hydrogen is not without problems. Chief among them are problems associated with tritium management via isotopic separation (due to the large hydrogen/tritium ratio) and tritium containment (arising from the presence of the reduced form of tritium and the potential permeation loss).

To overcome these problems, one needs to gain an understanding of the mechanism through which hydrogen enhances tritium release. This knowledge would also benefit the search for alternative "accelerator" materials besides hydrogen. Therefore, we have initiated a program to investigate the process of hydrogen adsorption onto lithium oxide surfaces. This program combines an experimental component involving temperature programmed desorption with computer simulations that model the hydrogen adsorption process. This work reports the results of the computer simulation.

\section{Method}

The technique that we have employed is the self-consistent-field Hartree-Fock method with linear-combination atomic orbitals modified to a crystalline environment. This $a b$ initio method contains no ad hoc adjustable parameters and uses crystal orbitals (COs) instead of molecular orbitals (MOs) [6]. These COs are defined (similar to the molecular orbital approach) as a linearcombination of atomic orbitals but with the periodic environment of the crystal built-in. This approach takes the extended nature of the crystalline materials into account. The CRYSTAL code [7] that we use for such calculations has adopted this $\mathrm{CO}$ approach.

However, for some low symmetry configurations such as kinks and ledges on surface step structures, the CRYSTAL approach may not be practical. A finite cluster approach, based on the GAUSSIAN90 code [8], is more suited to simulate these low symmetry configurations. Both codes have been utilized in a complementary manner. The main emphasis of the present work is to investigate the possibility of the dissociative hydrogen chemisorption on the unrelaxed terrace sites on $\mathrm{Li}_{2} \mathrm{O}$ surfaces, with the CRYSTAL code being the principal tool used. 
One of the keys to a successful $a b$ initio calculation is obtaining a good basis set to represent the electronic structure of the species. In the case of lithium oxide, its bonding characteristic is strongly ionic. In free space, the $\mathrm{O}^{2-}$ is an unstable ion; however, in crystalline $\mathrm{Li}_{2} \mathrm{O}$, the anion is stabilized by the surrounding cation environment (in our case, lithium). Recent calculations on bulk crystalline $\mathrm{Li}_{2} \mathrm{O}$ done by Dovesi et al. [9] have indicated that the optimized basis set, [14s/6p] and [7s/1p] for oxygen and lithium, yields lattice constant, elastic constants, and central zone phonon frequencies in good agreement with experimental values. We have adopted this crystalline basis set [9] for our calculations involving lithium oxide. For hydrogen, we have used the basis set [7s/1p], obtained by Dovesi [10], where the calculated equilibrium Hartree-Fock bond length of $\mathrm{H}_{2}$ of $0.738 \AA$ is in good agreement with its experimental value of $0.742 \AA$ [11].

\section{Results and Discussion}

The geometrical and the electronic structures of the bulk $\mathrm{Li}_{2} \mathrm{O}$, the stability of the $\mathrm{Li}_{2} \mathrm{O}$ surfaces, and dissociative hydrogen chemisorption on the $\mathrm{Li}_{2} \mathrm{O}$ surfaces are discussed in the following sections. The CRYSTAL code was used unless stated otherwise.

\subsection{Crystalline and Electronic Structure of $\mathrm{Li}_{2} \mathrm{O}$}

A number of experiments [12-14] have investigated the bulk properties of crystalline $\mathrm{Li}_{2} \mathrm{O}$, which has an anti-fluorite structure with the space group $F m 3 m$.

Figure 1 shows the calculated density of states (DOS) for the valence bands of the bulk $\mathrm{Li}_{2} \mathrm{O}$. This figure identifies the order of the occupied bands of the lithium and oxygen according to their energies. It also describes the number of states within an interval of energies between $\mathrm{E}$ and $\mathrm{E}+\mathrm{dE}$. The deepest band, not shown in the figure, occurs at $-555.910 \mathrm{eV}$, and is the 1s core orbital from oxygen. This band is followed by the two bands of the 1s orbital from lithium ( $\mathrm{Li}$ 1s), in the interval of -63.451 to $-63.105 \mathrm{eV}$. The $2 \mathrm{~s}$ orbital of oxygen (O 2s) appears between -31.231 and $-30.810 \mathrm{eV}$, and the highest bands, located between -13.554 and $-10.025 \mathrm{eV}$, are the $\mathrm{p}$ orbitals of oxygen (O 2p).

Our $a b$ initio calculation of crystalline $\mathrm{Li}_{2} \mathrm{O}$ indicates that it is a strongly ionic material for the following reasons. First, there is little overlap of the ionic charge distribution between the nearest neighboring $\mathrm{Li}-\mathrm{O}$ bonds, as indicated by the small and negative $(-0.01)$ bond population. This shows the limited presence of covalency. Secondly, as a consequence, the 
crystalline $\mathrm{Li}_{2} \mathrm{O}$ energy bands are well separated, and the lithium band does not contribute to the uppermost valence band of oxygen (Fig. 1, O 2p). Finally, from a Mulliken analysis of the charge distribution, the net charge of oxygen is $-1.94 \mathrm{e}$, very close to the value of $-2 \mathrm{e}$ expected from ideal ionic bonding.

\subsection{Stability of Unrelaxed $\mathrm{Li}_{2} \mathrm{O}$ Crystal Surfaces}

The surface study was carried out with a slab model. In this model, the semi-infinite $\mathrm{Li}_{2} \mathrm{O}$ crystal was simulated by a finite number of atomic layers parallel to the exposed face, reproducing the crystal geometry.

Lithium oxide crystal has three surfaces, namely, (100), (110), and (111). The (100) surface consists of alternating lithium layers and oxygen layers. The distance between the two layers is $1.143 \AA$. Each layer of the (110) surface is neutral and has both lithium and oxygen on the same plane. The layer separation is $1.617 \AA$. The (111) planes, for the smallest neutral unit, have two lithium layers with one oxygen layer. The distance between the lithium and the oxygen layers is $0.660 \AA$, and the distance between the two adjacent lithium layers is $1.320 \AA$. The stacking of the layers for these different surfaces is represented in Fig. 2.

Tasker [15] classified the charged layers into three classes, depending on the stacking sequences of the charged planes as one moves into the bulk of the crystal. The stacks of (100) planes are charged and have a dipole moment $(\mu)$ perpendicular to the planes (Fig. 2a). Addition of an extra neutral unit of two planes to the (100) surface creates dipole-dipole interaction, which will affect the energy of ions in the bulk of the crystal. The potential, therefore, never settles to its normal bulk value, and the surface energy does not converge. Thus, the (100) surface is energetically unstable and, therefore, will not be considered further in this work. Unlike the (100) planes, the (110) layers are built up from a stack of neutral layers (Fig. 2b). Both lithium and oxygen ions are present on each plane in a ratio such that the total charge is zero. The (110) surface is energetically stable since no dipole moment is created by the layer. Addition of (110) planes on the surface will have no electrostatic effect on an ion in the bulk. The (111) planes exhibit two different stackings. For one of these, the surface which terminates with the cation layer [Fig. $2 c$ (i)] has no net dipole moment and is stable. The other, which starts with the anion layer [Fig. $2 \mathrm{c}$ (ii)], has a non-zero moment and causes the surface to be unstable. To our knowledge, no experimental study has been done on the ordering and facet properties of $\mathrm{Li}_{2} \mathrm{O}$ surfaces. There has been an 
crystalline $\mathrm{Li}_{2} \mathrm{O}$ energy bands are well separated, and the lithium band does not contribute to the uppermost valence band of oxygen (Fig. 1, O 2p). Finally, from a Mulliken analysis of the charge distribution, the net charge of oxygen is $-1.94 \mathrm{e}$, very close to the value of $-2 \mathrm{e}$ expected from ideal ionic bonding.

\subsection{Stability of Unrelaxed $\mathrm{Li}_{2} \mathrm{O}$ Crystal Surfaces}

The surface study was carried out with a slab model. In this model, the semi-infinite $\mathrm{Li}_{2} \mathrm{O}$ crystal was simulated by a finite number of atomic layers parallel to the exposed face, reproducing the crystal geometry.

Lithium oxide crystal has three surfaces, namely, (100), (110), and (111). The (100) surface consists of alternating lithium layers and oxygen layers. The distance between the two layers is $1.143 \AA$. Each layer of the (110) surface is neutral and has both lithium and oxygen on the same plane. The layer separation is $1.617 \AA$. The (111) planes, for the smallest neutral unit, have two lithium layers with one oxygen layer. The distance between the lithium and the oxygen layers is $0.660 \AA$, and the distance between the two adjacent lithium layers is $1.320 \AA$. The stacking of the layers for these different surfaces is represented in Fig. 2.

Tasker [15] classified the charged layers into three classes, depending on the stacking sequences of the charged planes as one moves into the bulk of the crystal. The stacks of (100) planes are charged and have a dipole moment $(\mu)$ perpendicular to the planes (Fig. 2a). Addition of an extra neutral unit of two planes to the (100) surface creates dipole-dipole interaction, which will affect the energy of ions in the bulk of the crystal. The potential, therefore, never settles to its normal bulk value, and the surface energy does not converge. Thus, the (100) surface is energetically unstable and, therefore, will not be considered further in this work. Unlike the (100) planes, the (110) layers are built up from a stack of neutral layers (Fig. 2b). Both lithium and oxygen ions are present on each plane in a ratio such that the total charge is zero. The (110) surface is energetically stable since no dipole moment is created by the layer. Addition of (110) planes on the surface will have no electrostatic effect on an ion in the bulk. The (111) planes exhibit two different stackings. For one of these, the surface which terminates with the cation layer [Fig. $2 c$ (i)] has no net dipole moment and is stable. The other, which starts with the anion layer [Fig. 2c (ii)], has a non-zero moment and causes the surface to be unstable. To our knowledge, no experimental study has been done on the ordering and facet properties of $\mathrm{Li}_{2} \mathrm{O}$ surfaces. There has been an 
experimental study on the properties of (100) and (111) surfaces of $\mathrm{UO}_{2}$ (fluorite crystalline structure) determined by LEED (Low Energy Electron Diffaction) [16]. This study indicates that the (100) surface of uranium dioxide is also not stable.

The surface energy (SE) of (110) and (111) surfaces can be calculated with the following equation [17]:

$$
\mathrm{SE}=\left(n E^{b}-E^{n}\right) / 2 a
$$

where the denominator 2 is included because the surface energy is calculated with respect to one surface only; $n$ denotes the number of layers, in this case $n=1,2,3, \ldots$ for $(110)$ and $n=3,6,9, \ldots$ for (111); $E^{b}$ is the total energy (per $\mathrm{Li}_{2} \mathrm{O}$ ) of the bulk; $E^{\mathrm{n}}$ represents the total energy (per $n \mathrm{Li}_{2} \mathrm{O}$ ) of the n-layer slab; and $a$ is the surface unit cell area. Figure 3 shows the convergence of the surface energy of the stable (110) and (111) surfaces as the number of layers increases. The surface energy of (111) converges to $0.679 \mathrm{~J} \mathrm{~m}^{-2}$, while the (110) converges to $1.443 \mathrm{~J} \mathrm{~m}^{-2}$. A significant change in the surface energy, about $0.239 \mathrm{~J} \mathrm{~m}^{-2}$ occurs from the one- to two-layer (110) slab as a result of the uncoordinated ions on a single layer. The surface energies with the extended basis set [9] for (111) and (110) are about $15 \%$ and $11 \%$, respectively, lower than those calculated by Lichanot et al. [18]. In our work, the surface energy is $0.764 \mathrm{~J} \mathrm{~m}^{-2}$ lower for (111) than (110). This reflects the fact that the (111) surface is the natural cleavage plane in the anti-fluorite structure. Although the (111) surface is energetically more favorable, in reality, one expects that a faceted $\mathrm{Li}_{2} \mathrm{O}$ crystal would have both (110) and (111) surfaces present on a typical ceramic surface.

The electronic charge density contour plot of the three-layer (110) slab is shown in Fig. 4. A lack of covalency occurs, with a clear charge separation between the nearest Li-O neighbors. A similar ionic characteristic was observed for the (111) surface.

\subsection{Dissociative Hydrogen (H-H) Chemisorption on (110) and (111) Terraces}

The stability of the $\mathrm{Li}_{2} \mathrm{O}$ crystal surface is very important for investigating of the possibility of $\mathrm{H}-\mathrm{H}$ chemisorption on these stable (110) and (111) terraces. Terraces are atomically flat planes on a crystalline surface and may terminate at structures called "steps". Two classes of adsorption sites are considered below: heterolytic sites, in this case Li-O sites, and homolytic sites, such as $\mathrm{Li}-\mathrm{Li}$ and $\mathrm{O}-\mathrm{O}$ sites. 


\subsubsection{H-H Chemisorption on the Heterolytic Site of (110) and (111) Terraces}

Figures 5 and 6 show a part of the extended top layer of the (110) terrace and the projection of the three (111) layers. To study $\mathrm{H}-\mathrm{H}$ chemisorption on these terraces, we set up locations, within a unit cell, to place two hydrogen atoms. The unit cell of (110) and (111) surfaces is defined by basis vectors $\left(a_{1}, a_{2}\right)$ and $\left(b_{1}, b_{2}\right)$ as shown in Figs. 5 and 6 , respectively. The adsorption locations of the two hydrogen atoms being considered are also shown in these figures. Dissociative hydrogen sites are denoted by $\mathrm{H}(1) \mathrm{H}(2), \mathrm{H}(1) \mathrm{H}(3)$, and $\mathrm{H}(1) \mathrm{H}(4)$, where, for example, $\mathrm{H}(1) \mathrm{H}(2)$ means that, at location 1, one of the hydrogen atoms is on top of oxygen and the other hydrogen is on top of lithium at location 2. To find the hydrogen positions at a defined location on the surface, we have constrained the hydrogens to lie in a plane that is perpendicular to the surface; have optimized the $\mathrm{H}-\mathrm{H}$ distance (d), tilting angle $(\theta)$, height (h); and have allowed the $\mathrm{H}-\mathrm{H}$ to shift parallel to the surface (s). These quantities are represented in Fig. 7. For simplification, we located the minimum total energy with respect to the four parameters $(d, \theta, h, s)$. We started with varying the $h$ parameter to find the minimum total energy while keeping the other three parameters constant. At the optimized $h$, we varied the $d$ and kept $\theta$ and $s$ constant. By using the optimized $h$ and $d$, we then found the optimized $\theta$ while $s$ kept constant. Finally, at optimized $h, d$, and $\theta$, we varied the $s$ and found the final minimum total energy. Note that the model was set up such that the dissociative hydrogen appears only on top of surfaces; no hydrogen appears below the surfaces.

For each given $\mathrm{H}-\mathrm{H}$ at a particular location, the calculations were done for one-, two- and three-layer (110) and for three (111) layer. Surface coverages of $100 \%$ and $50 \%$ were also considered for the n-layer slab (where $n=1,2$, and 3 ) for the (110) surface and $100 \%$, $50 \%$, and $25 \%$ for the three-layer (111) surface. The $100 \%$ surface coverage means that each unit cell of the slab contains a dissociative hydrogen $(\mathrm{H}-\mathrm{H}) ; 50 \%$ and $25 \%$ surface coverages represent an $\mathrm{H}-\mathrm{H}$ within each repeated cell that is two and four times larger than the original unit cell, respectively.

Heat adsorption $\mathrm{E}_{\mathrm{ch}}$ of the hydrogen at each reaction site is calculated by the following equation,

$$
E_{c h}=E^{n}(H-H)-\left[E^{n}+E\left(H_{2}\right)\right]
$$

where $E^{n}(H-H)$ represents the minimum total energy where dissociative hydrogen is chemisorbed at a given location (with the optimized $h, d, \theta$, and $s$ ) on the surface, $E^{n}$ denotes the total energies 
of an n-layer slab, and $\mathrm{E}\left(\mathrm{H}_{2}\right)$ denotes the energy of the free hydrogen molecule. The convention for Eq. (2) is as follows: if $E_{c h}$ is negative, then the chemisorption is exothermic; if $E_{c h}$ is positive, the chemisorption is endothermic.

\subsubsection{Heats of Adsorption}

Table 1 lists the calculated heat of adsorption at the given locations (Figs. 5 and 6 ) for the (110) and (111) terraces. As the number of layers increases from two to three layers, the $\mathrm{H}-\mathrm{H}$ chemisorption energies on the (110) surface, particularly at $\mathrm{H}(1) \mathrm{H}(3)$, tend to become less endothermic. We have also studied the heat adsorptions of dissociative hydrogen at the given locations on four- and six-layer (110) slabs. The calculated results indicate no further change of the adsorption energy for $n \geq 3$. Thus, all subsequent calculations are for the three-layer slab.

In Fig. 5 for a one-layer (110) slab, each anion is surrounded by four cations. This arrangement is less coordinated compared with six cations for each anion on a twolayer (110) slab. Consequently, as shown in Fig. 3, a one-layer (110) slab is more reactive than slabs with more layers. Although a one-layer (110) slab is not a realistic model for a surface, this configuration could be used to understand the role of the lower coordination number of oxygen on surface step structures such as kinks and ledges. On a one-layer (110) slab with $100 \%$ surface coverage of $\mathrm{H}-\mathrm{H}$, the chemisorption state has an energy of $-0.93 \mathrm{eV}$, for which one hydrogen attaches to the oxygen and the other hydrogen is attached between two lithiums (Fig. 5).

\subsubsection{Electronic Structure}

Figure 8 illustrates the density of states (DOS) for a one-layer slab with a (110) surface, and $100 \%$ surface coverage, before and after chemisorption. Before chemisorption (finer lines), the uppermost valence bands are the $O 2 p$ bands indicated by three peaks (denoting $2 p_{x}, 2 p_{y}$, and $2 p_{z}$ bands). In the range of energies between -10.962 and $-9.942 \mathrm{eV}$, the DOS is dominated by the $O 2 p_{x}$ band, while from -9.942 to $-9.420 \mathrm{eV}$ one finds mainly the $O 2 p_{y}$ band. The narrow $O 2 p_{z}$ band occurs between -9.420 and $-9.380 \mathrm{eV}$. The $O 2 p_{z}$ orbital lies perpendicular to the surface, while the $O 2 p_{x}$ and $2 p_{y}$ orbitals are oriented parallel to the surface. The $\mathrm{O} 2 \mathrm{p}_{\mathrm{z}}$ plays the key role in the interaction with the hydrogen. 
Table 1. The calculated Hartree-Fock bond lengths (d) of dissociated hydrogen and the adsorption energies $\left(\mathrm{E}_{\mathrm{ch}}\right)$ for $\mathrm{n}=1,2$, and 3 layers. Results obtained from CRYSTAL.

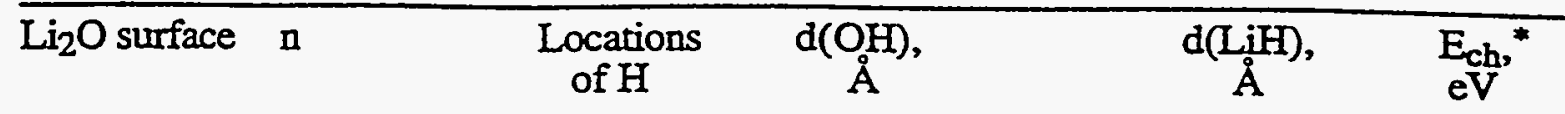

(110)

[Fig. 5]

\begin{tabular}{|c|c|c|c|c|}
\hline 1 & $\mathrm{H}(1) \mathrm{H}(2)$ & $\begin{array}{l}0.96 \\
(0.97)\end{array}$ & $\begin{array}{l}1.54 \\
(1.56)\end{array}$ & $\begin{array}{l}0.94 \\
(1.15)\end{array}$ \\
\hline & $\mathrm{H}(1) \mathrm{H}(3)$ & $\begin{array}{l}0.96 \\
(0.97)\end{array}$ & $\begin{array}{l}1.59 \\
(1.60)\end{array}$ & $\begin{array}{c}-0.93 \\
(1.03)\end{array}$ \\
\hline & $\mathrm{H}(1) \mathrm{H}(4)$ & $\begin{array}{l}0.96 \\
(0.97)\end{array}$ & $\begin{array}{l}2.04 \\
(1.57)\end{array}$ & $\begin{array}{l}\mathbf{- 0 . 6 4} \\
(1.24)\end{array}$ \\
\hline 2 & $\mathrm{H}(1) \mathrm{H}(2)$ & $\begin{array}{l}0.98 \\
(0.97)\end{array}$ & $\begin{array}{l}1.57 \\
(1.57)\end{array}$ & $\begin{array}{l}1 . \overline{1} 1 \\
(2.27)\end{array}$ \\
\hline & $\mathrm{H}(1) \mathrm{H}(3)$ & $\begin{array}{l}0.96 \\
(0.96)\end{array}$ & $\begin{array}{l}1.69 \\
(1.73)\end{array}$ & $\begin{array}{l}0.57 \\
(1.02)\end{array}$ \\
\hline & $\mathrm{H}(1) \mathrm{H}(4)$ & $\begin{array}{l}0.96 \\
(0.96)\end{array}$ & $\begin{array}{l}2.20 \\
(2.21)\end{array}$ & $\begin{array}{l}0.86 \\
(1.43)\end{array}$ \\
\hline 3 & $\mathrm{H}(1) \mathrm{H}(2)$ & $\begin{array}{l}0.97 \\
(0.97)\end{array}$ & $\begin{array}{l}1.57 \\
(1.58)\end{array}$ & $\begin{array}{l}1.54 \\
(1.82)\end{array}$ \\
\hline & $\mathrm{H}(1) \mathrm{H}(3)$ & $\begin{array}{l}0.96 \\
(0.96)\end{array}$ & $\begin{array}{l}1.65 \\
(1.72)\end{array}$ & $\begin{array}{l}0.33 \\
(0.79)\end{array}$ \\
\hline & $\mathrm{H}(1) \mathrm{H}(4)$ & $\begin{array}{l}0.96 \\
(0.96)\end{array}$ & $\begin{array}{l}2.18 \\
(2.21)\end{array}$ & $\begin{array}{l}0.61 \\
(1.05)\end{array}$ \\
\hline
\end{tabular}

(111)

[Fig. 6]

$\begin{array}{llll}\mathrm{H}(1) \mathrm{H}(2) & 1.1 & 1.48 & 3.65 \\ & (1.0) & (1.55) & (2.96) \\ & {[1.0]} & {[1.70]} & {[2.70]} \\ \mathrm{H}(1) \mathrm{H}(3) & 1.0 & 1.60 & 3.24 \\ & (1.0) & (1.60) & (2.24) \\ & {[1.0]} & {[1.65]} & {[1.95]} \\ \mathrm{H}(1) \mathrm{H}(4) & 1.0 & 2.22 & 2.73 \\ & (1.0) & (2.25) & (2.10) \\ & {[1.0]} & {[2.33]} & {[1.74]}\end{array}$

${ }^{*}$ The calculated adsorption energies are listed for various surface coverages. The $25 \%$, $50 \%$, and $100 \%$ surface coverages are represented by the square brackets, parentheses, and no brackets or parentheses, respectively. 
Table 2. The calculated Hartree-Fock bond lengths (d) of dissociative hydrogen and the adsorption energies $\left(\mathrm{E}_{\mathrm{ch}}\right)$. Results obtained from GAUSSIAN90.

$\begin{array}{llccc}\mathrm{Li}_{2} \mathrm{O} \text { surface } & \text { Clusters } & \begin{array}{c}\text { Locations } \\ \text { of } \mathrm{H}\end{array} & \mathrm{d}(\mathrm{OH}), & \AA\end{array} \quad \begin{gathered}\mathrm{d}(\mathrm{LiH}), \\ \AA\end{gathered}, \begin{gathered}\mathrm{E}_{\mathrm{ch}}, \\ \mathrm{eV}\end{gathered}$

(110)

[Fig. 5]

$\begin{array}{lllll}\mathrm{Li}_{22} \mathrm{O}_{11}{ }^{\dagger} & \mathrm{H}(1) \mathrm{H}(2) & 0.97 & 1.73 & 2.13 \\ & \mathrm{H}(1) \mathrm{H}(3) & 0.96 & 1.72 & 1.44 \\ & \mathrm{H}(1) \mathrm{H}(4) & 0.96 & 2.28 & 2.11 \\ \mathrm{Li}_{32} \mathrm{O}_{16}{ }^{\dagger \dagger} & \mathrm{H}(1) \mathrm{H}(2) & 0.97 & 1.75 & 1.91 \\ & \mathrm{H}(1) \mathrm{H}(3) & 0.96 & 1.74 & 1.50 \\ & \mathrm{H}(1) \mathrm{H}(4) & 0.96 & 2.28 & 1.96\end{array}$

(111)

[Fig. 6]

$\begin{array}{lllll}\mathrm{Li}_{18} \mathrm{O}_{9}+\dagger \dagger & \mathrm{H}(1) \mathrm{H}(2) & 1.0 & 1.90 & 1.60 \\ & \mathrm{H}(1) \mathrm{H}(3) & 1.0 & 2.30 & 2.23 \\ & \mathrm{H}(1) \mathrm{H}(4) & 1.0 & 2.28 & 1.00\end{array}$

tRepresenting the finite two (110) layers.

thepresenting the finite three (110) layers by adding the two (110) layers with its first layer, denoted by the filled circles in Fig.5.

tttRepresenting the finite three (111) layers. 
The thicker lines in Fig. 8 are the DOS in the presence of dissociative hydrogen at $\mathrm{H}(1) \mathrm{H}(3)$ (see Fig. 5). In the dissociative chemisorption state, the $\mathrm{O} 2 \mathrm{~s}$ band is stabilized downward by a band shift of about $4.5 \mathrm{eV}$. For the $\mathrm{O} 2 \mathrm{p}$ bands, the $2 \mathrm{p}_{\mathrm{x}}$ and $2 \mathrm{p}_{\mathrm{y}}$ bands are also shifted by about $3.58 \mathrm{eV}$. The narrow band between -16.770 and $-16.410 \mathrm{eV}$ represents the formation of $\mathrm{OH}^{-}$as a result of overlapping between the $\mathrm{O} 2 \mathrm{p}_{z}$ and $\mathrm{H} 1 \mathrm{~s}$ orbitals. There is no contribution from the $2 \mathrm{p}_{\mathrm{x}}$ and $2 \mathrm{p}_{\mathrm{y}}$ orbitals in the $\mathrm{O}-\mathrm{H}$ bond. A gap of $1.2 \mathrm{eV}$ is created between the $2 p_{z}$ and both the $2 p_{x}$ and $2 p_{y}$ bands. The band that lies between -9.470 and $-7.960 \mathrm{eV}$ represents the $\mathrm{H}^{-}$that bonds with the two cations in the form of $\mathrm{Li}^{+} \mathrm{H}^{-} \mathrm{Li}^{+}$.

The electronic charge densities of the $\mathrm{OH}^{-}$and $\mathrm{Li}^{+} \mathrm{HLi}^{-}$are shown in Figs. 9 and 10. A strong bond appears for $\mathrm{OH}^{-}$with a very localized electronic charge density, while for $\mathrm{Li}^{+} \mathrm{HLi}^{+}$the bonding is more ionic, with a clear-cut charge separation between $\mathrm{Li}^{+}$and $\mathrm{H}$. The $\mathrm{OH}$ and $\mathrm{LiH}$ bond lengths are 0.96 and $1.54 \AA$, respectively, which are closely comparable with the $\mathrm{OH}(0.97 \AA)$ and $\mathrm{LiH}(1.595 \AA)$ bond lengths reported for the gas phase [12]. For lower coverage ( $50 \%$ ) on a one-layer (110) slab, endothermic $\mathrm{H}-\mathrm{H}$ chemisorption occurs. This means that the exothermic dissociative hydrogen chemisorption at $100 \%$ coverage may be due to the lower coordination of the $\mathrm{Li}-\mathrm{O}$ site or to nearest neighbor adsorbate-adsorbate interactions.

Results from the n-layer (110) slab (where $\mathrm{n}=2$ and 3 ) with $100 \%$ surface coverage suggest that its $\mathrm{H}-\mathrm{H}$ chemisorption is endothermic. The density of states for the $\mathrm{O} 2 \mathrm{p}$ band of the (110) surface in the one-, two-, and three-layer systems (Fig. 11) indicates that the $\mathrm{O} 2 \mathrm{p}$ band stabilizes as additional layers are introduced. For example, in the case of two- and threelayers, the $O 2 p$ band shifts are about 2 and $2.6 \mathrm{eV}$, respectively, relative to the upper-limit $\odot 2 p$ of a one-layer slab. This means that as more layers are introduced to the surface, the surface becomes more stable, as expected. Lower surface coverage (50\%) also exhibits endothermic chemisorption (Table 1).

For the (111) surface, the $O 2 p$ band lies in the range close to the $O$ $2 p$ band of a one-layer (110) slab, at -10.638 to $-8.086 \mathrm{eV}$. However, only endothermic hydrogen chemisorption occurs on the (111) surface. One reason is screening of the lithium layers; as a result, it is energetically unfavorable for the $\mathrm{H}^{+}$to move close to the positively charged $\mathrm{Li}^{+}$layer before it can be chemisorbed by the $\mathrm{O}^{2-}$. 


\subsubsection{H-H Chemisorption on the Homolytic Site of (110) and (111) Terrace}

Calculations for the homolytic sites of the terrace, such as $\mathrm{Li}-\mathrm{Li}$ and $\mathrm{O}-\mathrm{O}$, indicate no $\mathrm{H}-\mathrm{H}$ chemisorption. For $\mathrm{H}-\mathrm{H}$ chemisorption to occur on the homolytic sites, it has to be in the form of either two $\mathrm{H}^{+}$or two $\mathrm{H}^{-}$ions, where each hydrogen attaches to two oxygens or two lithiums. For the $\mathrm{O}-\mathrm{O}$ site, each oxygen would have to release its valence electron, or each hydrogen would have to release its electron to the crystal environment, and the released electrons would have to be captured by the cations, forming neutral lithiums. For the $\mathrm{Li}-\mathrm{Li}$ site, each hydrogen would need to capture an electron from oxygen to form $\mathrm{H}^{-}$while the anion becomes $\mathrm{O}^{-}$. Such phenomena do not occur for the $\mathrm{Li}_{2} \mathrm{O}$ surface under equilibrium conditions since they require transferring electrons into the surrounding crystal environment. This is equivalent to creation of electronic defects (for example, neutral $\mathrm{Li}$ or $\mathrm{O}^{-}$). The surface band structure that we have obtained indicates that electronic disorder is energetically unfavorable. It is possible that electronic defects may occur under highly non-equilibrium conditions, such as irradiation, which creates electronic structure defects on the crystal surface. However, at equilibrium no homolytic chemisorption occurs.

\subsubsection{H-H Chemisorption on the Finite (110) and (111)Terraces}

To investigate chemisorption of a single $\mathrm{H}-\mathrm{H}$ site on the terrace (no adsorbateadsorbate interactions), the finite neutral clusters model (GAUSSIAN90 program [8]) was employed, as well as the same basis sets for both lithium and oxygen as were used for the extended crystalline model. Care was taken to construct a cluster in which the reaction sites have the correct environment to at least first nearest neighbors for both the cation and anion species. At the same time, enough additional ions were included to render the cluster neutral. The geometrical structures of the clusters representing the (110) and (111) terraces are shown in Figs. 5 and 6, respectively. The $\mathrm{Li}-\mathrm{Li}, \mathrm{Li}-\mathrm{O}$, and $\mathrm{O}-\mathrm{O}$ distances are the same as those on the crystal surface. In the present work, the $\mathrm{Li}_{22} \mathrm{O}_{11}$ cluster is constructed to simulate the two-layer (110) terrace (Fig. 5). For three-layers, the $\mathrm{Li}_{32} \mathrm{O}_{16}$ cluster is obtained by adding the first layer (defined by the filled circles in Fig. 5 ) to the $\mathrm{Li}_{22} \mathrm{O}_{11}$ cluster. The three (111) layers are represented by the $\mathrm{Li}_{18} \mathrm{O}_{9}$ cluster. 
Table 2 shows the calculated results for various locations of dissociative hydrogen on clusters which represent the (110) and (111) surfaces. Heat of adsorption is calculated from Eq. 2. The adsorption energies obtained from the crystalline surface model at the surface coverage below 100\% (see Table 1) and obtained from the cluster models (Table 2) indicate that dissociative hydrogen chemisorption on the (110) and (111) surfaces is endothermic.

In terms of the geometrical structure at the $\mathrm{H}-\mathrm{H}$ locations on both (110) and (111) surfaces (compare Table 1 and 2), the $\mathrm{OH}$ bond length obtained from the finite cluster and crystalline surface models is in good agreement. The $\mathrm{LiH}$ bond lengths are also in agreement, except at $\mathrm{H}(1) \mathrm{H}(2)$ for the two- and three-layer (110) slab and at $\mathrm{H}(1) \mathrm{H}(2)$ and $\mathrm{H}(1) \mathrm{H}(3)$ on the (111) surface. Furthermore, the adsorption energies obtained from the cluster and crystalline surface model (at lower surface coverage) are in agreement at the $\mathrm{H}(1) \mathrm{H}(2)$ location on the two- and threelayer (110) slab. The discrepancies, such in the LiH bond length and adsorption energy, occur due to the finiteness of the cluster. The environment around the cluster needs to be introduced in order to better describe the surface and hydrogen chemisorption. On the other hand, the crystalline surface model at lower surface coverage needs to be explored further.

\section{Summary}

Dissociative hydrogen chemisorption on the (110) and (111) terraces has been studied with the $a b$ initio Hartree-Fock technique. Both the finite cluster and extended crystalline models qualitatively agree that endothermic dissociative hydrogen chemisorption occurs on these terraces. The calculations for the (110) terraces in the n-layer slab model (where $\mathrm{n}=2$ and 3 ), indicate a metastable chemisorption and no chemisorption at the homolytic sites. Exothermic chemisorption with $100 \%$ coverage takes place for the case of a one-layer (110) slab around the $\mathrm{Li}-\mathrm{O}$ site. This is caused by the lower coordination of the oxygen and nearest neighbor adsorbate-adsorbate interactions. Although a one-layer (110) slab represents an unphysical surface, this model illustrates that a lower coordination environment, as in surface step structures such as kinks and ledges, may play an important role in the hydrogen chemisorption process. This will be investigated in the next state of our work. Although the oxygen (111) terrace has the same local coordination and similar energy range of $\mathrm{O} 2 \mathrm{p}$ orbital as it does in the (110) terrace, there is only endothermic hydrogen chemisorption. 
INSERT TABLE 2 HERE 
A number of approximations used in this study should be noted. First, correlation effects, which can be important in bond breaking and making, were not included. Second, more polarization functions may need to be introduced, particularly, along the bonding between surface site and hydrogen. Third, local relaxation of the surface was not considered. Future studies will take consideration of these effects, as well as use other types of basis sets, which may give an improved account of bond energetics.

\section{Acknowledgments}

We thank Prof. M. Seel (Michigan Technological University) for fruitful discussions. One of us (A.S.) would like to thank the Chemical Technology Division, the Division of Educational Program for the Laboratory Graduate Appointment, and Michigan Technological University for the graduate fellowship. The calculations using GAUSSIAN90 were carried on the IBM/SP1 at the Mathematics and Computer Science Division (ANL) and the ASCC facilities at MTU.

\section{$\underline{\text { References }}$}

[1] W. Dienst, D. Schild, and H. Werle, Kernforschungszentrum, Karlsruhe, Report KfK-5109, December 1992.

[2] O. D. Slagle, T. Takahashi, F. D. Hobbs, K. Noda, D. L. Baldwin, G. W. Hollenberg, and R. A. Verall, "Postirradition Examination of BEATRIX-II, Phase I," to be published in J. Nucl. Mater.

[3] H. Kwast, A. Kout, R. R. Muis, M. P. Stijkel, A. J. Flipot, and J. D. Elen, Fusion Engineering and Design 8 (1989) 359-364.

[4] R. G. Clemmer, P. A. Finn, R. F. Malecha, B. Misra, M. C. Billone, D. L. Bowers, A. K. Fischer, L. R. Greenwood, R. F. Mattas, S. W. Tam, R. B. Poeppel, G. T. Reedy, I. T. Dudley, F. F. Dyer, E. D. Clemmer, J. S. Watson, P. W. Fisher, J. R. Conlin, R. L. Childs, J. L. Scott, R. M. Arons, and A. E. Scandora, "The TRIO Experiment," Argonne National Laboratory, Argonne Report ANL-84-55, September 1984.

[5] H. Kwast, R. Conrad, R. May, S. Casadio, N. Roux, and H. Werle, "The Behaviour of Ceramic Breeder Materials with Respect to Tritium Release and Pellet/Pebble Mechanical Integrity," to be published in J. Nucl. Mater.

[6] G. Del Re, J. Ladik and Biczo, Phys. Rev. 155 (1967)997-1003; J.M. André, L. Gouverneur, and G. Leroy, Intern. J. Quantum Chem. 1 (1967)451-461. 
[7] R. Dovesi, C. Roetti, and V.R. Saunders, CRYSTAL92 program.

[8] M. J. Frisch, M. Head-Gordon, G. W. Trucks, J. B. Forseman, H.B. Schlegel, K. Ragavachari, M. A. Robb, J. S. Binkley, C. Gonzalez, D. J. Freeze, D. J. Fox, R. A. Whiteside, R. Seeger, C. F. Melius, J.Baker, R. L. Martin, L. R. Kahn, J. J. P. Stewart, S. Topiol, and J. A. Pople GAUSSIAN90 (Gaussian, Inc., Pittsburgh PA, 1990).

[9] R. Dovesi, C. Roetti, C. Freyria-Fava, and M. Prencipe, Chem. Phys. 156 (1991) 11.

[10] R. Dovesi, C. Ermondi, E. Ferrero, C. Pisani, and C. Roetti, Phys. Rev. B 29 (1984).

[11] W. J. Hehre et al., Ab Initio Molecular Orbital Theory (John Wiley, New York, 1986) pp.138 and 210.

[12] T. W. D. Farley, W. Hayes, S. Hull, R. Ward, M. T. Hutchings, and M. Alba, Solid State Ionics, 28-30 (1988)189.

[13] S. Hull, T. W. D. Farley, W. Hayes and M. T. Hutchings, J. Nucl. Mater. 160(1988) 125.

[14] T. W. D. Farley, W. Hayes, s. Hull, M. T. Hutchings, M. Alba and M. Vrtis, Physica B $156 \& 157(1989) 99$.

[15] P. W. Tasker, Surface Science 87 (1979) 315.

[16] T. N. Taylor and W. P. Ellis, Surface Science 77 (1978) 321.

[17] C. Pisani et al., Hartree-Fock Ab Initio Treatment of Crystalline Structure (Spring-Verlag, Berlin, Heidelberg 1988) p.136.

[18] Alber Lichanot, Michel Gelize, Christiane Larrieu, and Cesare Pisani, J. Phys. Chem. Solids 52 (1991) 1155. 


\section{Figure Captions}

Figure 1. The Hartree-Fock total density of states of crystalline $\mathrm{Li}_{2} \mathrm{O}$.

Figure 2. Stacking sequence of (100), (110), and (111) planes. The non-zero dipole moments $(\mu)$ occur on the $(100)$ and (111) planes, with the anion termination. $M$ denotes the $\mathrm{Li}^{+}$and $\mathrm{O}$ is $\mathrm{O}^{2-}$.

Figure 3. The Hartree-Fock surface energy $\left(\mathrm{J} \mathrm{m}^{-2}\right)$ versus number of layers for (110) and (111) planes.

Figure 4. Total electronic charge density map of the (110) surface with $0.003 \AA$ interval from one isoelectronic to the nearest isoelectronic contour.

Figure 5. Geometry of the two-layer (110) slab. The unit cell is defined by basis vectors $\mathbf{a}_{1}=(3.23,0.0,0.0) \AA$ and $\mathbf{a}_{2}=(0.0,4.57,0.0) \AA$. The locations of dissociative hydrogen are represented by $1,2,3$, and 4 .

Figure 6. Geometry of the three-layer (111) slab. The unit cell is defined by basis vectors $\mathbf{b}_{1}=(3.23,0.0,0.0) \AA$ and $\mathbf{b}_{2}=(-1.62,1.87,0.0) \AA$. The locations of dissociative hydrogen are represented by $1,2,3$, and 4 .

Figure 7. Location of $\mathrm{H}-\mathrm{H}$ with respect to $\mathrm{h}, \mathrm{d}, \theta$, and $\mathrm{s}$.

Figure 8. Density of states for a one-layer (110) slab. Before chemisorption is represented by the finer lines. The thicker lines represent the DOS where dissociative hydrogen is chemisorbed.

Figure 9. Total electronic charge density map of the $\mathrm{OH}^{-}$bond on a one-layer (110) slab with the contour interval of $0.003 \AA$.

Figure 10. Total electronic charge density map of the ionic bonding of $\mathrm{Li}^{+} \mathrm{H}^{-} \mathrm{Li}^{+}$on a onelayer (110) slab.

Figure 11. Schematic diagram of the total density of states of $\mathrm{O} 2 \mathrm{p}$ for the one-, two- and three-layer slab of the (110) surfaces. 
Total Density of States

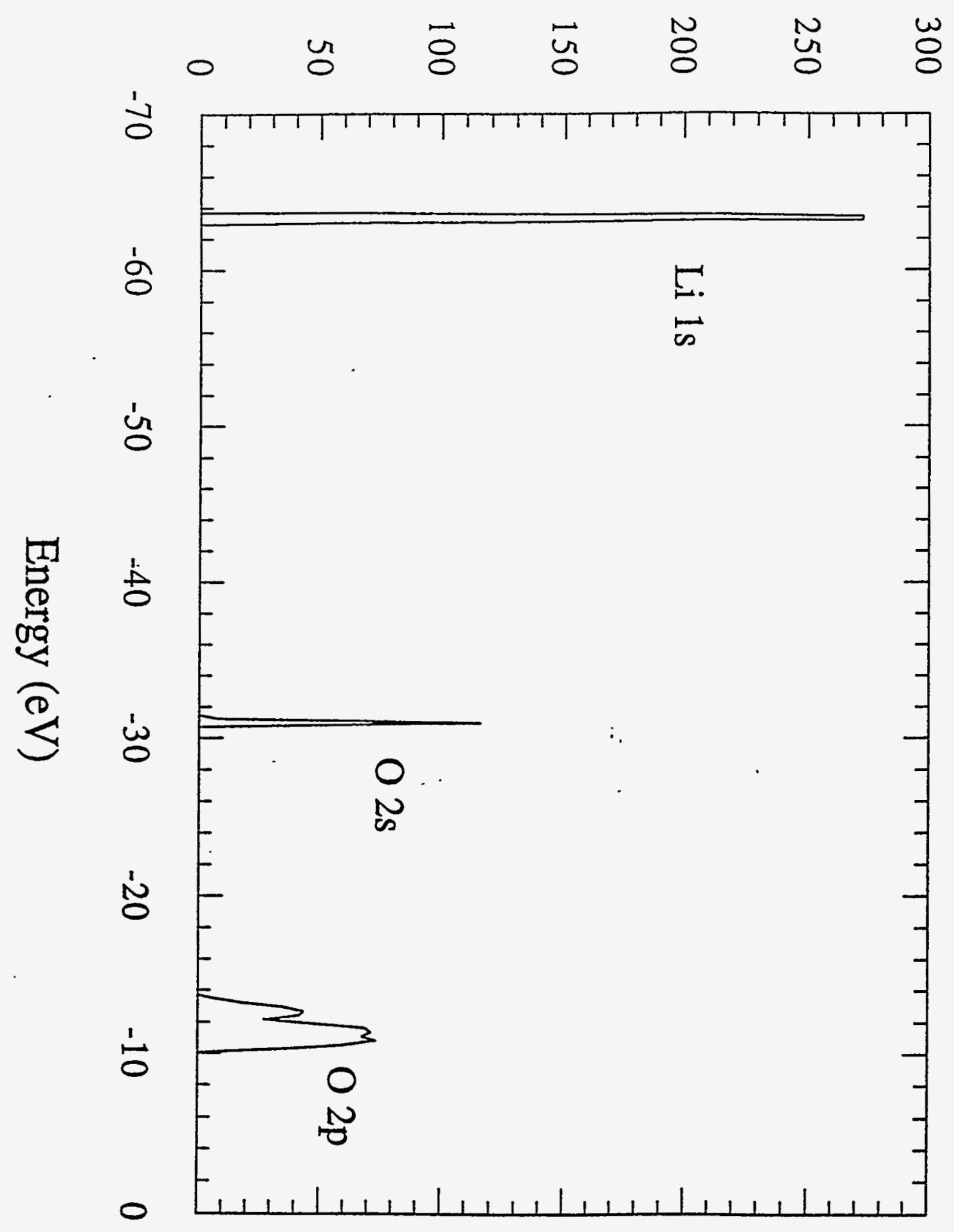




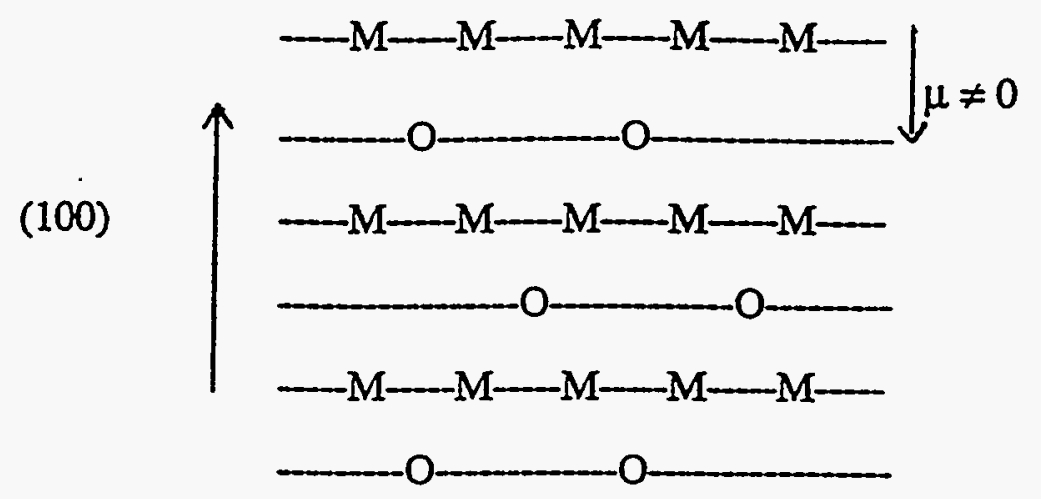

(a)

(110) $\left\{\begin{array}{l}-\mathrm{M}-\mathrm{O}-\mathrm{M}-\mathrm{M}-\mathrm{O}-\mathrm{M}-\mathrm{M}- \\ -\mathrm{M}-\mathrm{M}-\mathrm{O}-\mathrm{M}-\mathrm{M}-\mathrm{O}-\mathrm{M}- \\ -\mathrm{M}-\mathrm{O}-\mathrm{M}-\mathrm{M}-\mathrm{O}-\mathrm{M}-\mathrm{M}-\end{array}\right.$

(b)

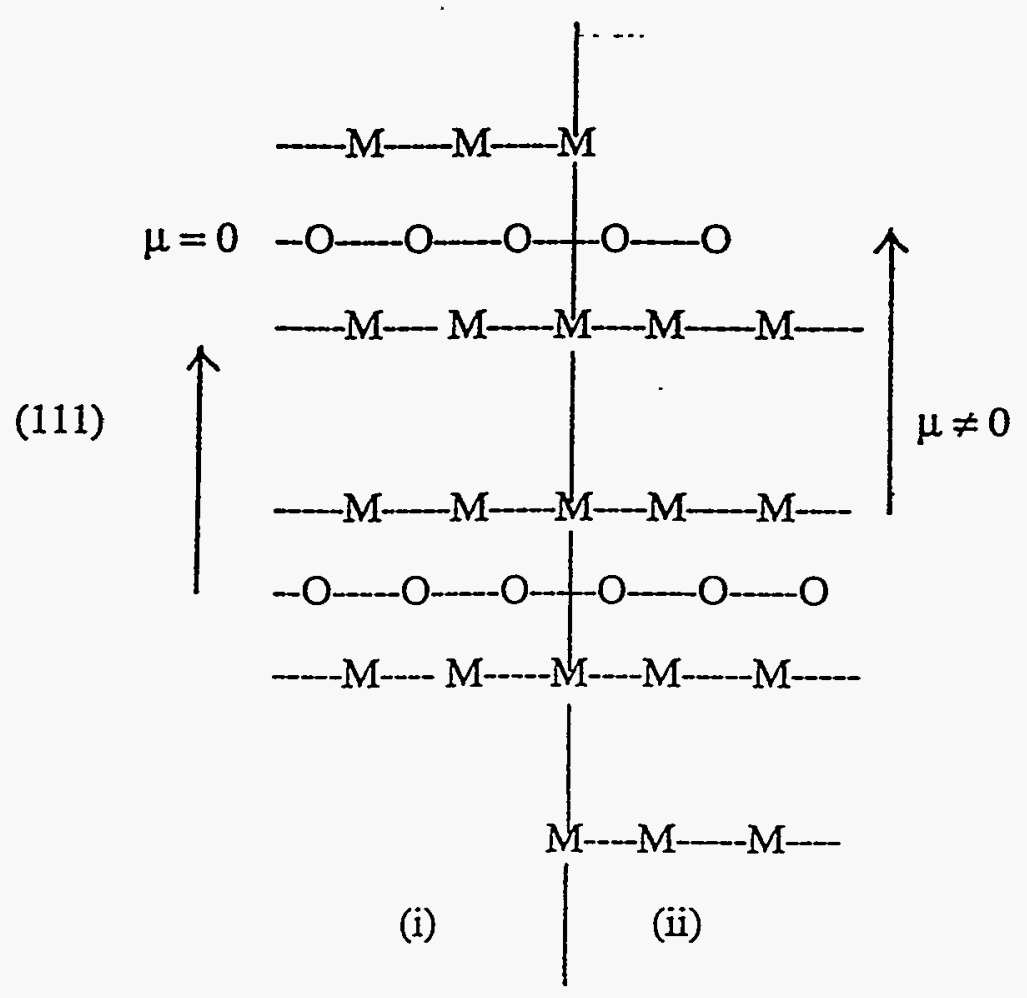

(c) 


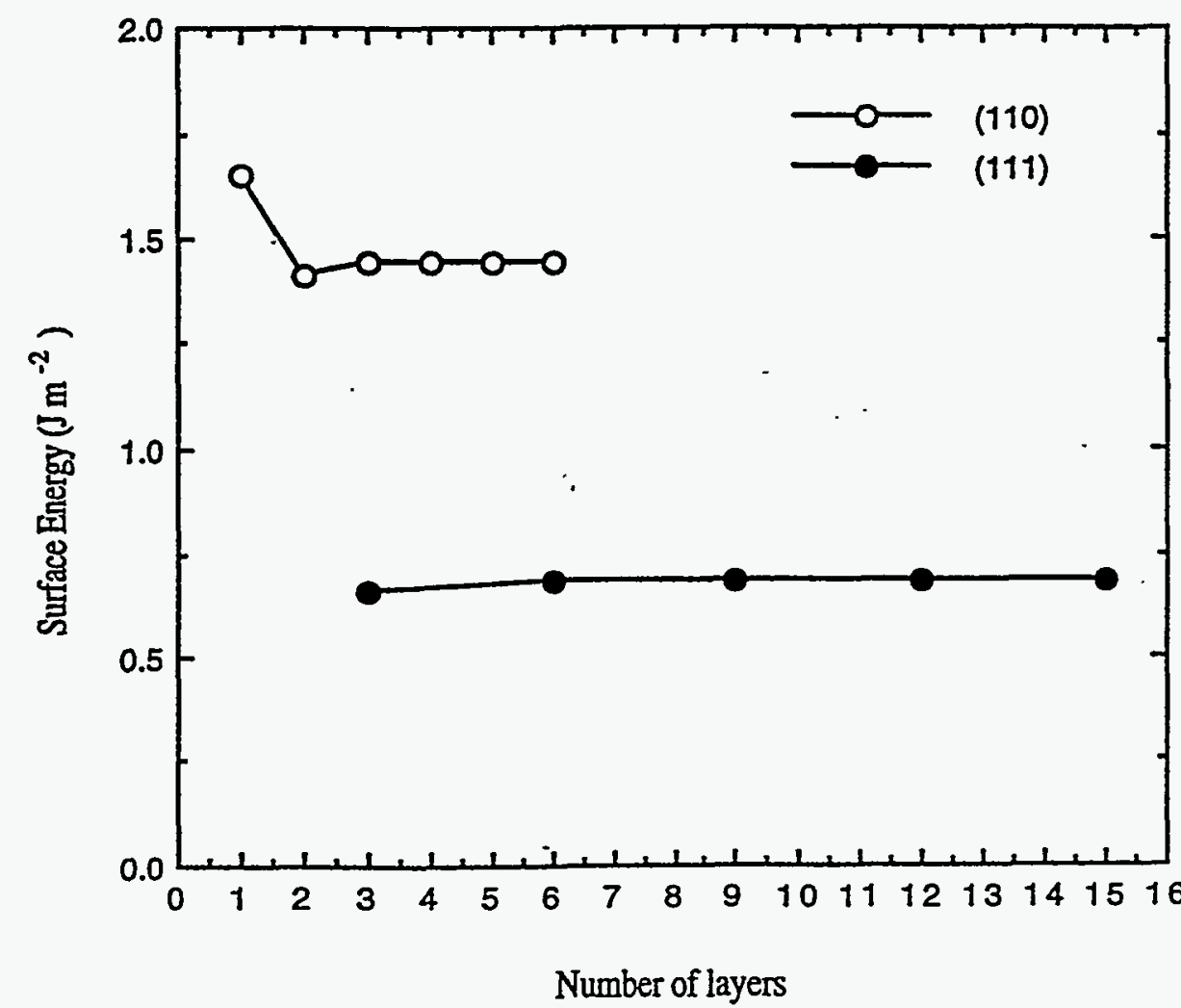




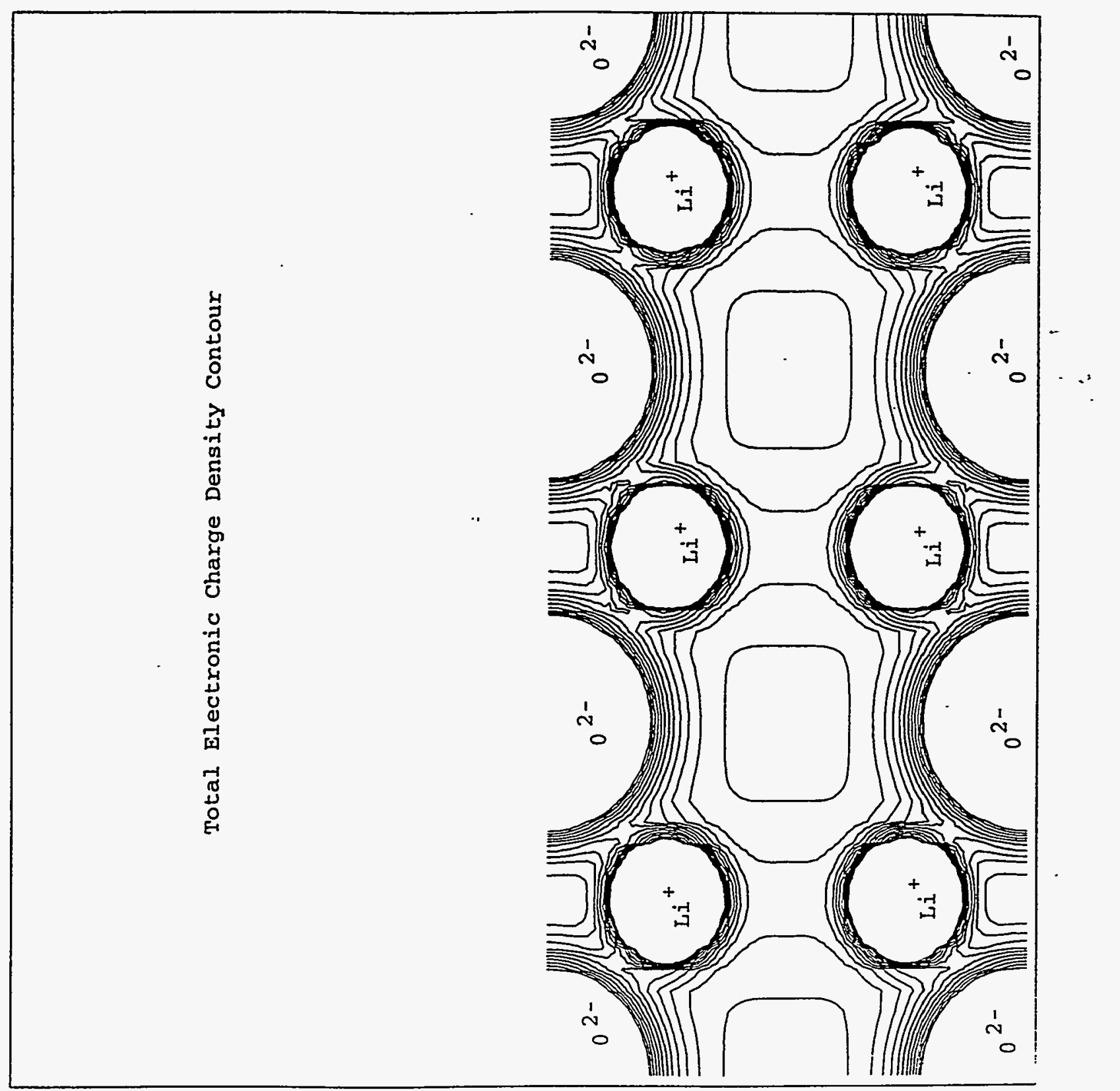




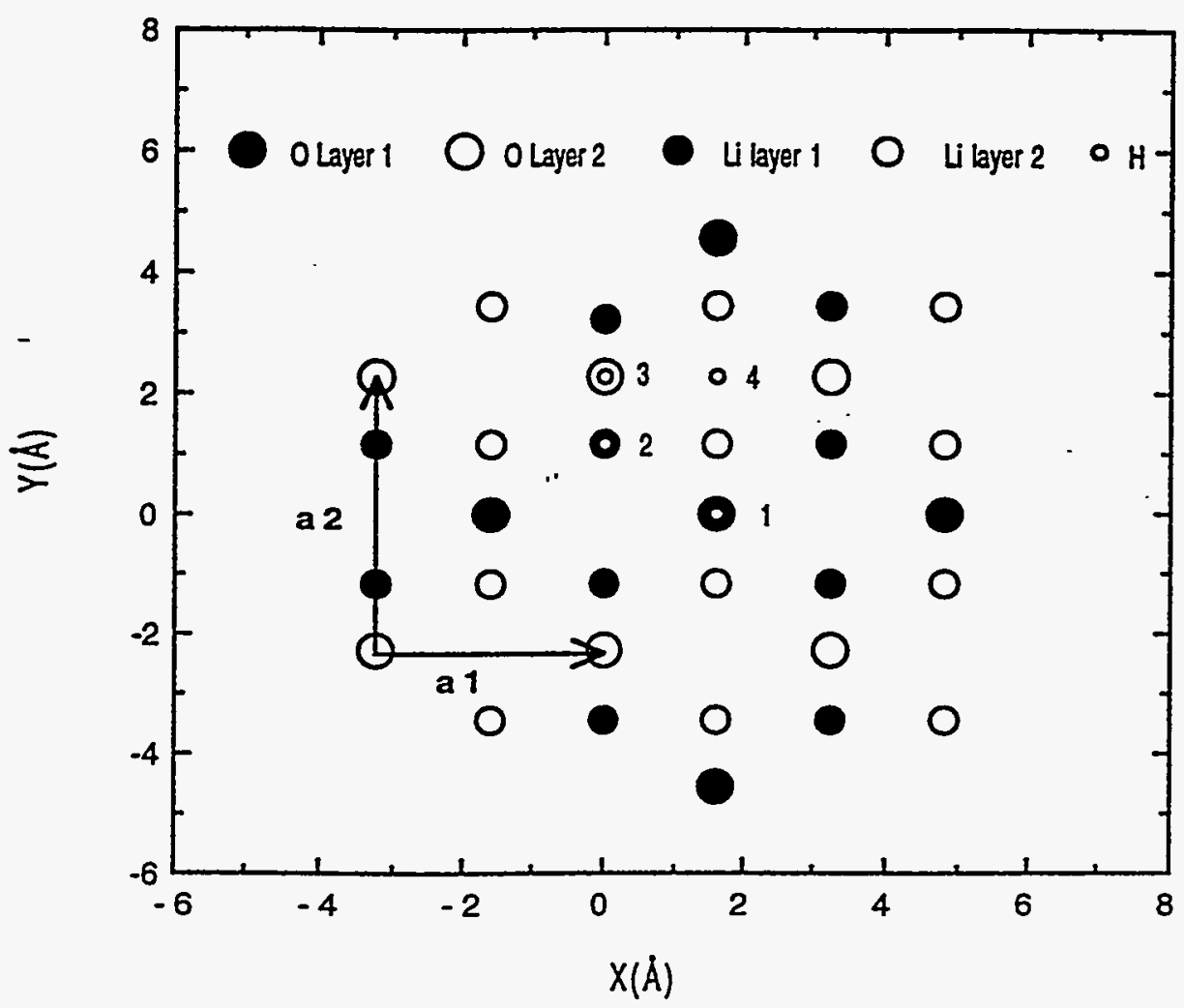




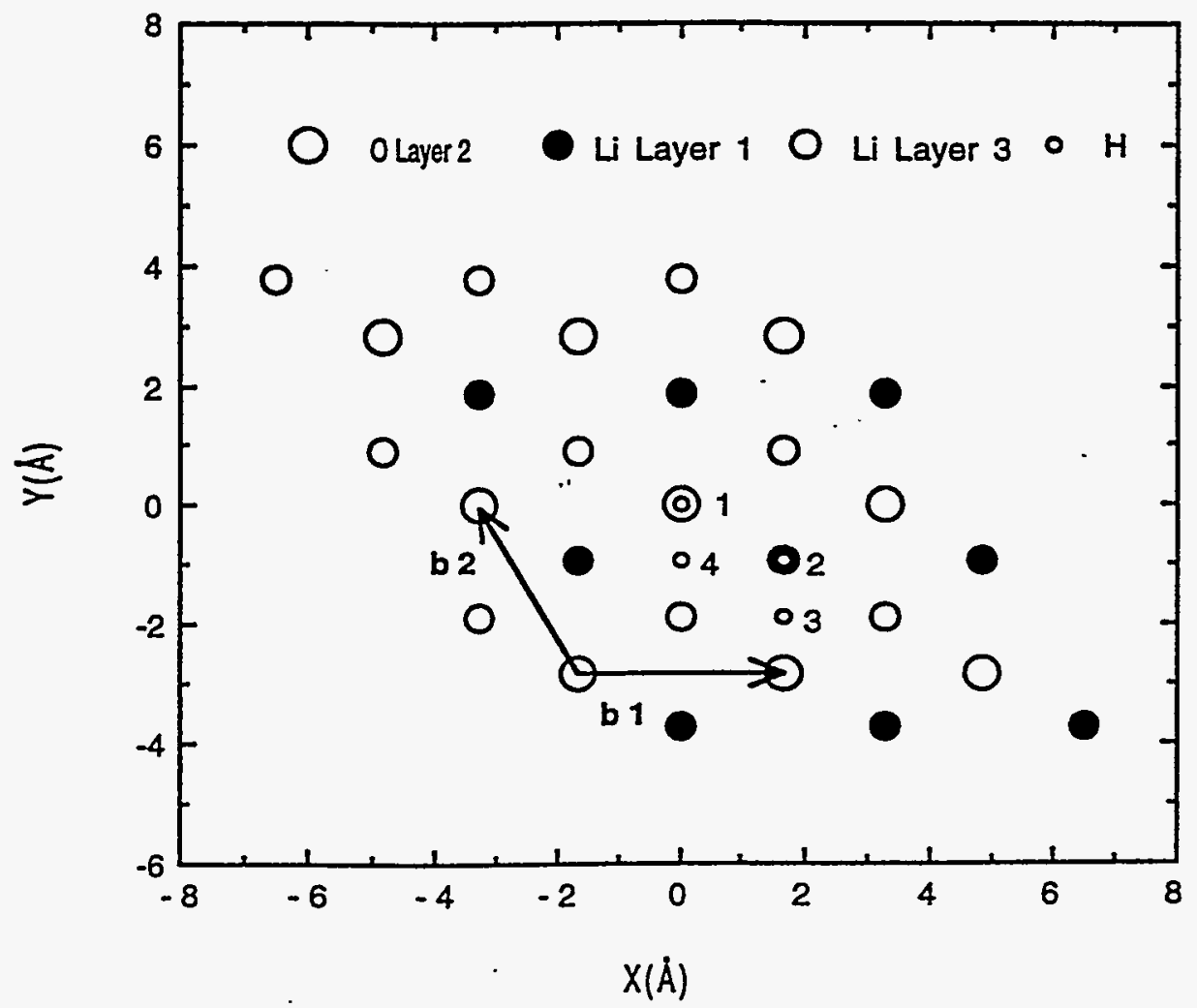




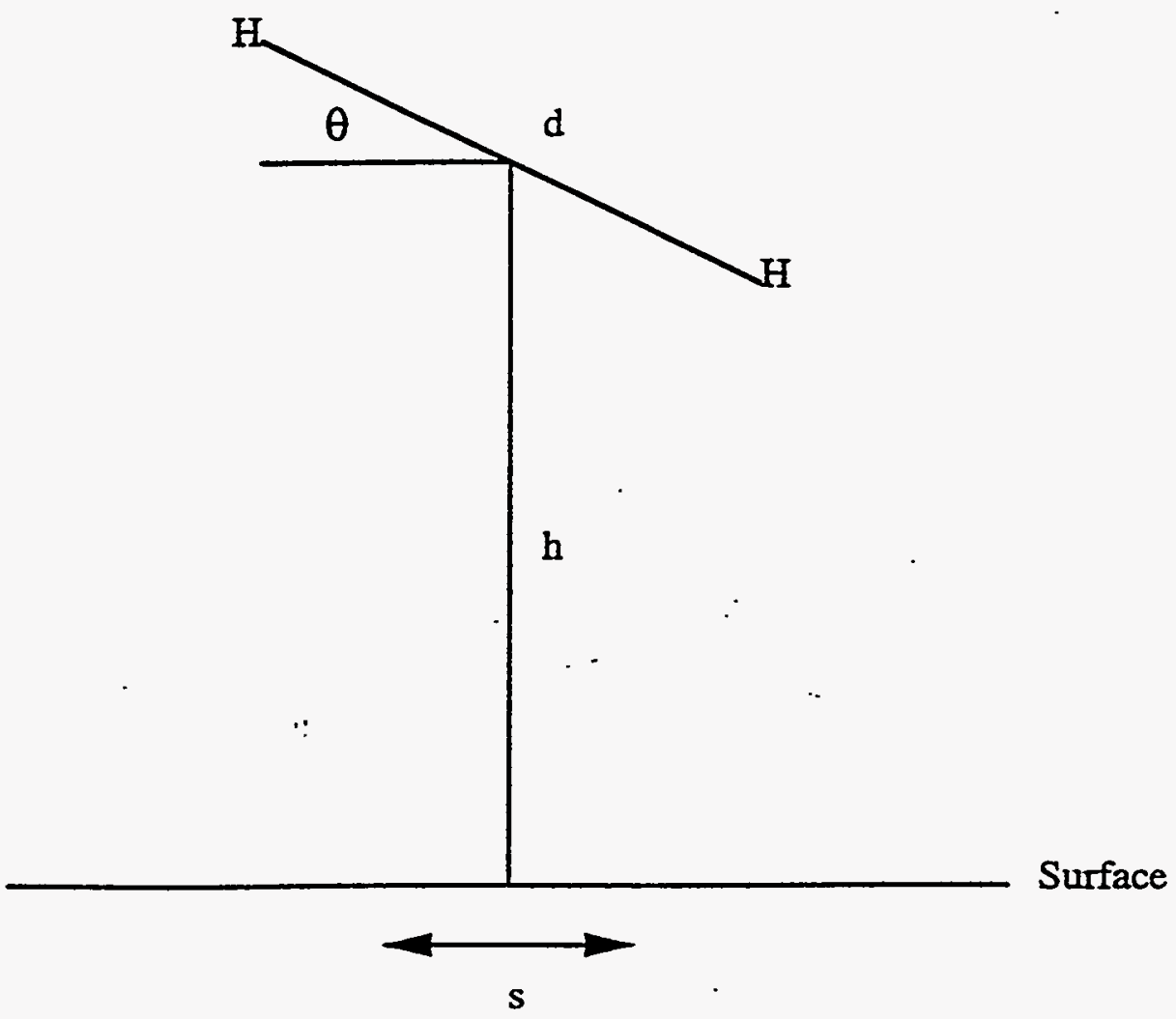


$\therefore \therefore . \cdots$

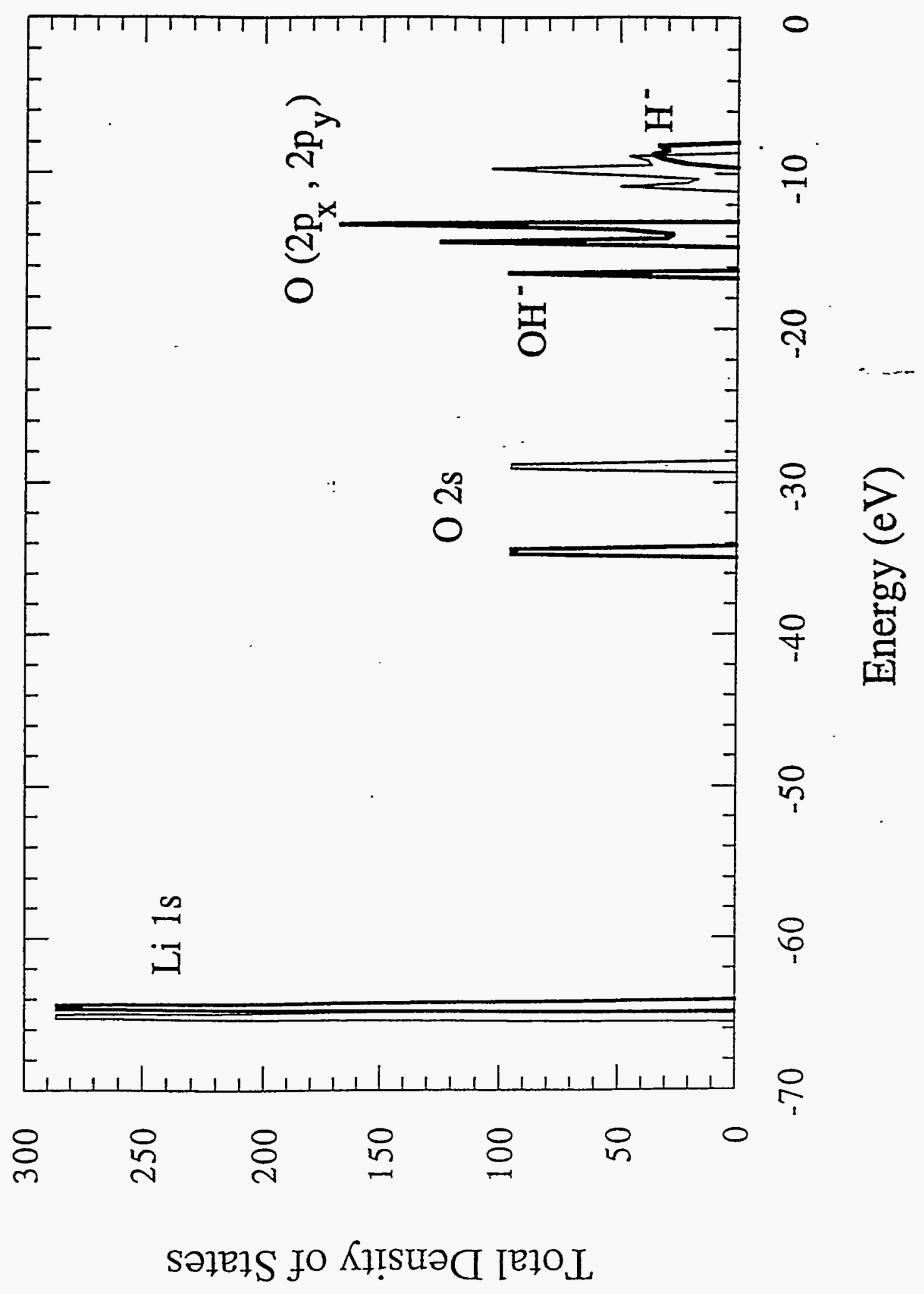




$$
\bar{\lambda}
$$




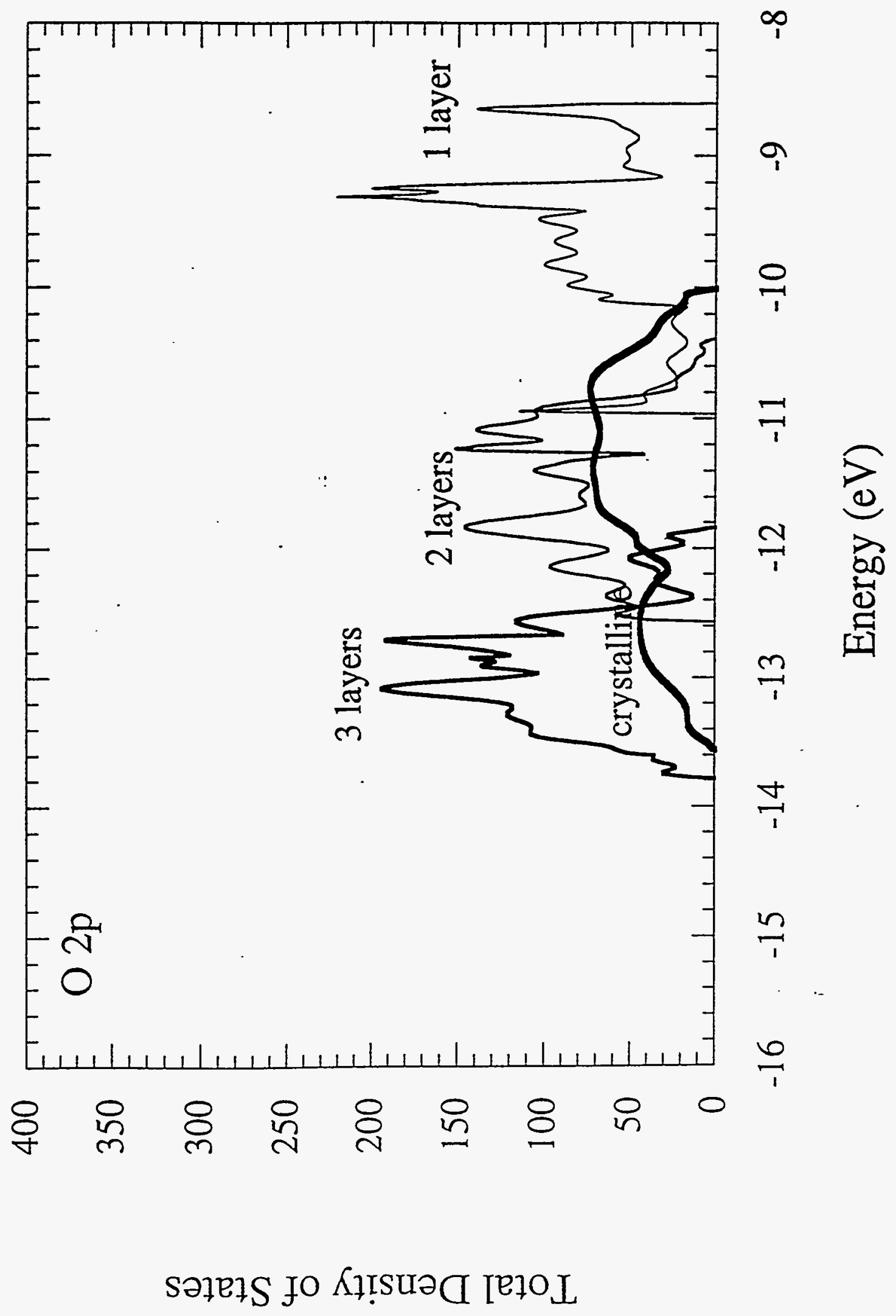

